\title{
Community-based pandemic preparedness: COVID-19 procedures of a Manitoba First Nation community
}

\author{
Grace Kyoon-Achan ${ }^{\star \dagger}$ and Lynda Wright ${ }^{\dagger}$
}

\begin{abstract}
The COVID-19 pandemic has impacted the Canadian health, social and economic landscape beginning early in 2020. Efforts to stem the viral tide have called into cooperation international, federal, and provincial governments. These governments are drawing on public health and socio-economic measures to prevent outbreaks in some cases and reduce infections and death rates in others. First Nations are a seemingly peripheral part of the general response, with communities being served by Indigenous Services Canada, a federal government institution responsible for First Nations health care. A participant observation process enabled the reporting of the community's steps in pandemic planning and preparation. We showcase the work being accomplished on the ground in Nisichawayasihk Cree Nation, a community in northern Manitoba. This includes strong local leadership, evidence-based planning and decision-making, pooling and coordinating resources, ongoing communication, traditional medicines and health approaches, planning for mental health supports, ensuring food security and general safety for community members. All levels of community-based leadership along with strong, measured and well-coordinated action are required to prevent the outbreak of viral infections in First Nation communities.
\end{abstract}

Key Words First Nations; pandemic; planning and preparation.

\section{INTRODUCTION}

First Nations (FN) communities in Canada are tucked within provincial health systems, with federal support, and often follow provincial and federal leads, requirements, and mandates on matters of national concern. The COVID-19 pandemic has tested the country's ability to plan, prepare for, and respond to a public health threat of global proportions. There is a paucity of literature outlining how FN have acted or should respond in the face of pandemics to protect their people and communities. Such information would highlight strengths, provide a reference and offer examples to other Indigenous communities on useful steps that can serve to protect people in rural or remote $\mathrm{FN}$ communities. By reason of remoteness and/or rural living, Indigenous communities face unique geographical barriers, differential access to health care services, and limited health care personnel, often resulting in poorer health and outcomes (Benchimol et al., 2018; Goodridge, Lawson, Rennie, \& Marciniuk, 2010; Harasemiw et al., 2018).
These challenges are exacerbated during national emergencies such as pandemics.

A report on lessons learned from the $2009 \mathrm{H} 1 \mathrm{~N} 1$ influenza pandemic in Canada, noted how structural and administrative deficiencies in managing the pandemic resulted in negative impacts on Indigenous communities even as they became disproportionately burdened by the disease. The report outlined challenges in responding to the H1N1 influenza pandemic that ranged from insufficient infection control, inadequate supplies and equipment, insufficient human resources and training to structural racism hampering the government's response and action in the case of Indigenous populations and communities. To remedy the situation for future incidents, the report recommended preventive planning, attending to existing social determinants of health, improved infrastructure, and designing context-specific interventions. However, the report provides limited express information on how Indigenous communities planned for or responded to the pandemic (National

\footnotetext{
Correspondence to: Grace Kyoon Achan, Ongomiizwin Research - Indigenous Institute of Health and Healing, University of Manitoba, Winnipeg, MB R3W OW3. E-mail: Grace.KyoonAchan@umanitoba.ca

To cite: Kyoon-Achan, G., \& Wright, L. (2020). Community-based pandemic preparedness: COVID-19 procedures of a Manitoba First Nation community. Journal of Community Safety and Well-Being, 5(2), 45-50. https://doi.org/10.35502/jcswb.131

(C) Author(s) 2020. Open Access. This work is distributed under the Creative Commons BY-NC-ND license. For commercial re-use, please contact sales@sgpublishing.ca.
}

g.PUBLISHING Published by SG Publishing Inc. CSKA Official publication of the Community Safety Knowledge Alliance. 
Collaborating Centre for Aboriginal Health, 2016), which is the focus of this article.

As the world reels in the wake of a new coronavirus pandemic, it has been invaluable to share information and useful practices from across countries and communities in order to contribute to wider disease prevention and management efforts. It is to this end that this article reports on the emergency planning and preparation procedures of Nisichawayasihk Cree Nation (NCN) a Manitoba FN that has so far been successful in preventing an outbreak of the new coronavirus pandemic in the community. NCN is located about 800 kilometers north of Winnipeg, Manitoba and about 80 kilometers north of Thompson, Manitoba which is its closest town. NCN is Cree-speaking, with about 4,500 residents and over 5,000 members. The community is bordered by three rivers (Burntwood, Footprint, and Rat) and lush forests. NCN is an enterprising community whose outlook, against a long colonial history, is to work diligently towards self-determination and local empowerment. This article is shared in the hopes of learning together and spurring on other Indigenous rural and remote communities.

\section{BACKGROUND}

The Coronavirus disease 2019 (COVID-19) caused by severe acute respiratory syndrome coronavirus 2 (SARS-CoV-2 previously known as 2019-nCoV) is unprecedented in its severity and transmissibility. COVID-19 hit an unprepared world by storm in late 2019 and unfolded in full view of concerned peoples and communities globally. From Wuhan Hubei province China, the initial epicenter where the virus is said to have started (Wu et al., 2020), the disease has now travelled far and wide, reaching 212 countries and infecting well over 3 million people with nearly 240,000 deaths worldwide (World Health Organization, 2020b). Many watched with keen interest as China struggled to curtail the spread of the virus and to understand its nature and transmission characteristics. As more information became available, it was understood that the virus had high severity and mortality rates. Severity was higher in older patients, disproportionately affected people with comorbidities, and most infected patients had a history of exposure to Wuhan or others who had recently travelled to Wuhan, the epicenter (Guan et al., 2020; Fan, Fan, Li, Shi, \& Liang, 2020; Liang et al., 2020; Xu et al., 2020).

Clinical symptoms were said to include a dry cough, runny nose, fever, and gastrointestinal infection symptoms (Guo et al., 2020; Lai, Shih, Ko, Tang, \& Hsueh, 2020). Imaging characteristics included presentation with bilateral, multifocal lung lesions detected using chest computed tomography (CT) scans (Fan et al., 2020; Xu et al., 2020; Zhang, Qiao, \& Zhang, 2020). It is now known that COVID-19 is also spread through human to human contact through the respiratory tract, mainly through droplets and close contact with infected persons (Guo et al., 2020; Lai et al., 2020; Wang et al., 2020; Yang et al., 2020). Transmission is also noted to be high in locations frequented by large numbers of people, such as retail stores (Wang et al., 2020). Other details about the virus are being documented to inform further action, with modeling studies giving pointers on the possible impact of the disease, depending on preventive measures assumed (Li et al., 2020; Zhang et al., 2020).
The COVID-19 spread attained pandemic scale on March 11, 2020 (World Health Organization, 2020a). It arrived on Canada's shores through Ontario in January 2020, when a man who had travelled back from Wuhan, China, presented with symptoms and tested positive for the virus (Government of Canada, 2020a). To date, over 40,000 cases and 2,000+ deaths have been reported in Canada (Government of Canada, 2020b). Canada is also reporting known disease characteristics of cough, dyspnea, headache, general weakness, and pneumonia of greater severity in people with pre-existing conditions of cardiac disease, respiratory disease, and diabetes, with a near balance in gender distribution-55\% female and $45 \%$ male-and rising numbers of community transmissions (Government of Canada, 2020b).

\section{THE CANADIAN RESPONSE}

The Canadian government joined international collaboration and coordination efforts with the World Health Organization (WHO) and also responded locally by keeping all Canadians frequently updated, putting out travel advisories against nonessential travel to high incidence countries. There have been repatriations of Canadians abroad, response coordination with all provinces and territories as well as with Indigenous leaders in the form of issuing public health guidance for surveillance and infection prevention and control (Government of Canada, 2020c). Funding was also disbursed to provinces and territories, but by and large, provinces and territories are responsible for activating public health measures such as reducing gatherings in public and providing direct health care to patients. Schools, places of worship, and non-essential retail shops were advised to shut down and companies were asked to operate from home as much as possible. Attention was also pledged to the needs of "federal populations," including FN peoples and communities (Government of Canada, 2020c).

In Manitoba, Indigenous Services Canada (ISC) has been working with FN to support emergency response activities mainly by providing up-to-date COVID-19 information through weekly teleconferences, online (https://www.gov. mb.ca/covid19/updates/index.html) and by daily provincial COVID-19 updates and news conferences (Government of Manitoba, 2020). ISC has also distributed emergency preparation support funding and delivered Personal Protective Equipment (PPE) to an unverified number of FN communities, in keeping with federal commitments (Indigenous Services Canada, 2020).

It is interesting that the federal government made a commitment, in the face of the COVID-19 pandemic, to support access to health services that would be comparable with that of other Canadians (Government of Canada, 2020c). Historically, First Nations in Canada have not enjoyed comparable health services-or comparable health for that matter (Adelson, 2005; Barnabe et al., 2017; Beavis et al., 2015; Bombak \& Bruce, 2012; Chen et al., 2015; Eggertson, 2015; Gone et al., 2019). This has led to calls for government accountability for persistent neglect (Abdolhosseini et al., 2016; TRC, 2015). Poorer structural and social determinants also elevate disease risk in FN populations and communities (Bethune et al., 2018; Browne et al., 2016; Coombes et al., 2018; Gracey \& King, 2009; Greenwood \& de Leeuw, 2012; Hajizadeh, Hu, Bombay, \& Asada, 2018), so that quasi-emergency planning tends to 
perpetually be operating in FN homes and communities. While the country seemed to have suddenly awakened to the importance of a comparable health services approach to address a pandemic, FN can be said to be reasonably acquainted with acute planning in daily unpredictable life. Regardless, that announcement was a welcome development to NCN, where people were stunned by the rapid spread of COVID-19 and welcoming of the federal response efforts overall.

\section{METHODS}

A participant observation lens (Anzul, Ely, Freidman, Garner, \& McCormack-Steinmetz, 1991) was applied to guide information collection and reporting structure and accuracy. Observation included attendance and documenting of meetings, planning sessions, teleconferences, and reviewing COVID-19 situational updates and information. A summary of key activities over a six-week period (March 1 to April 30, 2020) is reported.

\section{Gathering Strength to Combat COVID-19}

Manitoba FN that had their eyes on the news and could imagine the potential havoc COVID-19 could wreak on their populations began assessing available resources to protect people and communities. NCN was guided along by a systems-thinking orientation in which all factors that could influence the outbreak and spread of COVID-19 were considered. Causal loop diagrams were drawn to depict case scenarios of how the disease could make its way into and spread within the community (Bradley, Mansouri, Kee, \& Garcia, 2020) or conversely, how loopholes could be blocked to prevent an outbreak. The community recognized that in order to prevent or control an outbreak, appropriate clinical and public health measures would need to be in place. The community needed to: 1) Understand the virus, its nature and transmission characteristics; 2) Evaluate the population and any factors that could make them susceptible and yield poor disease outcomes, for example elderly patients or those with predisposing conditions; 3) Determine disease transmission routes, such as travel-related or community transmission potential; 4) Develop infection control pathways. In the case of COVID-19, there are no therapeutics or vaccines (Guo et al., 2020; Lai et al., 2020; Yang et al., 2020).

Preventing and Controlling COVID-19 in the Community Having come through the H1N1 pandemic in 2009, FN understood that rural and remote communities plan differently than the general urban population (Mostaco-Guidolin, Bowman, Greer, Fisman, \& Moghadas, 2012; Mostaco-Guidolin, Greer, Sander, Wu, \& Moghadas, 2011; Mostaco-Guidolin, Towers, Buckeridge, \& Moghadas, 2013). The best line of defense would be to ensure as much as possible that there are no outbreaks in the first place. NCN leadership comprised of Chief and Council $(\mathrm{C} \& \mathrm{C})$ members, directors and managers of programs in the community, emergency and public health teams (which was to become to community's pandemic planning and preparation team [PPPT]), promptly sprang into action. The PPPT came together and started with a review of a pre-existing emergency response plan. Key emergency procedures, roles and responsibilities of $C \& C$, Nurse-in-Charge (NIC), the local Emergency Management
Office (EMO), and officers were identified and highlighted. Available human resources for possible redeployment were identified as were other skilled people in the community, such as hunters, medicine pickers, and auto and electrical repairpersons. These skills and capacities would be useful in the event of a community emergency trigger and possible lockdown. The PPPT also identified and prepared locations that could be quickly converted for clinic, testing, and quarantine use and took comprehensive stock of available equipment and supplies at the local nursing station.

\section{Specific Steps}

These are the specific steps that were taken as part of the community's pandemic planning and preparation.

1. Reviewing emergency plans-A key step in our community pandemic planning was having emergency response documents in place. This provided a rallying document for the public health team and community leadership. It also provided a sense of preparedness and confidence that the community was ahead of the pandemic with an implementable plan.

2. Joint decision-making-Joint decision-making with public health, nursing staff and community leadership was crucial. The public health team provided information and recommendations on infection prevention and control measures, including hyper disinfecting high-traffic areas, such as the school and recreational facilities in the community. The NIC provided information on testing, priority populations, and facility capacities in the community. Leadership informed the community through memos and fielded questions. Memos and factsheets were distributed throughout the community to guide individual and corporate action. For example, the local school and teachers were duly briefed on the nature, transmission, and current situation of COVID-19. C\&C observed and responded to teachers' concerns during the town hall-style briefing, and those discussions led to the decision to shut the school until further notice. This happened well ahead of provincial announcements of school closures for the rest of the year. This measure to prevent a possible outbreak among students and teachers happened quickly because all concerned leadership was together in assessing the situation and jointly making decisions along with the school board and education general authority.

3. Reviewing evidence-C\&C requested and received expert public health information on COVID-19. The public health department conducted a comprehensive review of literature on the disease and provided evidence summaries to the PPPT. The team wanted to operate and make evidence-backed decisions based on information and ongoing updates from reliable sources.

4. Traditional health knowledge-The emergency PPPT called for medicine people in the community to prepare traditional medicines for the traditionally inclined in the community. Medicine people in the community went out on the land harvesting and 
preparing medicines for the entire community. Preparations were to support personal immunity and to help disinfect households and public spaces. Traditional health practices were also conducted by medicine people for psychosocial and spiritual support. Sweat lodges, smudging, prayers, and landbased activities observing stipulated physical distancing measures were offered. Medicine bundles were readied and placed at the local counselling department for pick-up and distributed from house to house, especially to Elders who could not go to pick up their bundles.

5. Mental health and well-being-There was a significant amount of fear and anxiety in the population regarding contracting the infection and anxiety about what could happen to the community if there was an outbreak. Studies show that this tendency towards fear, anxiety, and worry in emergencies is commonplace (Mawson, 2005). Fear and anxiety can be worsened by loneliness - caused by self-isolation and quarantine measures in some instancesamong individuals, older adults, and even health care workers and requires mental health supports (Banerjee \& Rai, 2020; Cai et al., 2020; Goethals et al., 2020; Zhang \& Ma, 2020). A mental health therapist and trained counsellors in the community were placed on alert to provide support when necessary to community members and for workers. They were to be proactive in reaching out to people who may be vulnerable in such cases, such as Elders, the bereaved or people in palliative care or struggling with predisposing conditions. There were intentional moments of prayers at meetings and planning sessions to help people stay calm and rely on the Great Spirit.

6. Securing public trust in authorities-C\&C, together with the public health team, decided early on to frequently share accurate and reliable information with the community. This was intended to curb misinformation leading to panic, which was already quite rampant as people lifted false, incomplete, or contradictory information from Facebook or other social media. Some of the information circulating on social media was not consistent with public health or scientific evidence on COVID-19. It was also crucial to communicate all possible risks to individuals and the community as a way to motivate action and propel full adoption of recommended public health measures of hand washing, cough etiquette, physical distancing, and PPE use when in inevitable contact with an infected person.

7. Communication-The Chief provided information and updates on the local radio in both Cree and English. Information sheets and flyers were also developed or obtained from reliable sources and hand delivered to all homes in the community. In addition, weekly memos were placed on the community's website and emailed to all staff. Communication kept the community abreast of any action the leadership was taking to protect the people. All avenues were explored so that no one would be left behind on information or any measures being taken.
For example, a physical distancing measure was instituted, restricting mass gatherings to not more than 50 people at first, and then to not more than 10 people within two weeks. The nature and culture of the community is that people operate in warm closeknit relationships. Visiting, hugging, and sharing food are common, especially during community activities (fishing derbies, sports, powwow, etc.) and gatherings during funerals. Proper and adequate communication helped the community understand and observe physical distancing.

8. Infection control measures-The public health department conducted training sessions on PPE, provided information on disinfecting households, and frequently used spaces and homemade disinfecting sprays and wipes with bleach which can be effective against viral pathogens. Store-bought disinfecting supplies were also distributed to families with young children and those who would normally receive homecare services. Homes and living conditions were assessed during the doorto-door information distributions, families needing extra supplies were supported or advocated for to receive additional services, such as mould removal, food, and cleaning supplies.

9. Stockpiling and supports-Food packages were prepared for the most vulnerable members of the community and especially those with young children. The packages included non-perishable food items, cleaning supplies, personal hygiene supplies, diapers, and baby wipes. The local store was encouraged to stockpile groceries as uncertainty mounted regarding the COVID-19 pandemic. In the nearby town of Thompson, the pandemic had created panic and pandemonium with people hyper-shopping and items being out of stock for weeks at a time. Ordering those items directly into the community was a way to have sensible rations and prevent community members from commuting in and out of the community several times to see if needed items had become available in stores in town. Being assured of food and supplies had a calming effect on the population, making it easier to implement necessary public health measures such as stay-at-home orders.

10. Community safety-Following a systems analysis of possible COVID-19 impact on the community, C\&C instituted a pre-emptive local state of emergency on March 20, 2020. A lockdown of the community also came into effect on March 22, 2020. NCN was one of the first communities to institute these measures in northern Manitoba. Community members with business outside of the community were advised to complete all obligatory business they had outside the community within a stipulated number of days and return to the community in preparation for the lockdown. The PPPT required the development of contingency work and business plans including taking stock of essential workers who were to stay on active duty during the lockdown. This step helped cushion any economic impact and maintain business function on a scaled back but active level. 
11. Accounting for everyone-The PPPT implemented procedures for receiving all returnees into the community within a specified time period. This included members who had been living in urban centres and some who had become homeless and used homeless shelters in towns and cities. Spaces were prepared in which returnees could be quarantined and monitored for symptoms over a twoweek period before reuniting with families. If they developed any symptoms, there were procedures laid out on homecare monitoring or safe transfer to hospital care. This step welcomed all members back home while also keeping the rest of the community safe.

\section{CONCLUSION}

Collaborative planning is crucial for community preparedness during pandemics, or indeed any emergencies. Reliable and frequent information provides guidance and calms the community while decisions are made on the best paths forward. NCN has demonstrated that FN have the capacity to pull together, pool resources and fight for the well-being of our people. As at the writing of the article, there are no COVID-19 cases recorded in the community. This makes a compelling case for community-based pandemic preparedness for all FN communities. Outside resources are important and do play a significant role, and community preparation is a bedrock without which chaotic situations can and do become uncontrollable, manifesting in fear, anxiety, and panic. A strong and prepared leadership is instrumental in maintaining confidence and marshalling resources to protect FN people and communities during pandemics.

\section{ACKNOWLEDGEMENTS}

We thank the Nisichawayasihk Cree Nation Pandemic Planning and Preparation Team, who continue to work tirelessly to protect the people and community. This work was not funded.

\section{CONFLICT OF INTEREST DISCLOSURES}

The authors have no conflicts of interest to declare.

\section{AUTHOR AFFILIATIONS}

*Ongomiizwin Research - Indigenous Institute of Health and Healing, University of Manitoba Winnipeg, MB; ${ }^{+}$Nisichawayasihk Cree Nation, Family and Community Wellness Centre, Nelson House, MB.

\section{REFERENCES}

Abdolhosseini, P., Bonner, C., Montano, A., Young, Y. Y., Wadsworth, D., Williams, M., \& Stoner, L. (2016). Should the governments of "developed" countries be held responsible for equalizing the Indigenous health gap? Global Health Promotion, 23(4), 70-72. doi:10.1177/1757975915574255

Adelson, N. (2005). The embodiment of inequity: health disparities in aboriginal Canada. Canadian Journal of Public Health, 96/Suppl 2), S45-S61.

Anzul, M., Ely, M., Freidman, T., Garner, D., \& McCormack-Steinmetz, A. (1991). Doing Qualitative Research: Circles Within Circles. London, UK: Routledge.

Baneriee, D., \& Rai, M. (2020). Social isolation in COVID-19: the impact of loneliness. International Journal of Social Psychiatry, 20764020922269. doi:10.1177/0020764020922269
Barnabe, C., Jones, C. A., Bernatsky, S., Peschken, C. A., Voaklander, D., Homik, J., ... Crowshoe, L. F. (2017). Inflammatory arthritis prevalence and health services use in the First Nations and non-First Nations populations of Alberta, Canada. Arthritis Care Research (Hoboken), 69(4), 467-474. doi:10.1002/acr.22959

Beavis, A. S., Hoijati, A., Kassam, A., Choudhury, D., Fraser, M., Masching, R., \& Nixon, S. A. (2015). What all students in healthcare training programs should learn to increase health equity: perspectives on postcolonialism and the health of Aboriginal Peoples in Canada. BMC Medical Education, 15, 155. doi:10.1186/s12909-015-0442-y

Benchimol, E. I., Kuenzig, M. E., Bernstein, C. N., Nguyen, G. C., Guttmann, A., Jones, J. L., ... Kaplan, G. G. (2018). Rural and urban disparities in the care of Canadian patients with inflammatory bowel disease: a population-based study. Clinical Epidemiology, 10, 1613-1626. doi:10.2147/clep.S178056

Bethune, R., Absher, N., Obiagwu, M., Qarmout, T., Steeves, M., Yaghoubi, M., ... Tikoo, R. (2018). Social determinants of selfreported health for Canada's indigenous peoples: a public health approach. Public Health, 176, 172-180. https://doi.org/10.1016/i. puhe.2018.03.007

Bombak, A. E., \& Bruce, S. G. (2012). Self-rated health and ethnicity: focus on Indigenous populations. International Journal of Circumpolar Health, 71, 18538. doi:10.3402/iijch.v71i0.18538

Bradley, D. T., Mansouri, M. A., Kee, F., \& Garcia, L. M. T. (2020). A systems approach to preventing and responding to COVID-19. EClinicalMedicine, 100325. doi:10.1016/i.eclinm.2020.100325

Browne, A. J., Varcoe, C., Lavoie, J., Smye, V., Wong, S. T., Krause, M., ... Tu, D. (2016). Enhancing health care equity with Indigenous populations: evidence-based strategies from an ethnographic study. BMC Health Services Research, 16(1), 544. doi:10.1186/ s12913-016-1707-9

Cai, W., Lian, B., Song, X., Hou, T., Deng, G., \& Li, H. (2020). A cross-sectional study on mental health among health care workers during the outbreak of Corona Virus Disease 2019. Asian Journal of Psychiatry, 51, 102111. doi:10.1016/i.ajp.2020.102111

Chen, L., Xiao, L., Auger, N., Torrie, J., McHugh, N. G., Zoungrana, H., \& Luo, Z. C. (2015). Disparities and trends in birth outcomes, perinatal and infant mortality in Aboriginal vs. non-Aboriginal populations: a population-based study in Quebec, Canada 1996-2010. PLOS One, 1019), e0138562. doi:10.1371/journal.pone.0138562

Coombes, J., Hunter, K., Mackean, T., Holland, A. J. A., Sullivan, E., \& Ivers, R. (2018). Factors that impact access to ongoing health care for First Nation children with a chronic condition. BMC Health Services Research, 18(1), 448. doi:10.1186/s12913-018-3263-y

Eggertson, L. (2015). Red tape blocks care for Aboriginal children. Canadian Medical Association Journal, 187151, 317-318. doi:10.1503/ cmaj.109-5001

Fan, N., Fan, W., Li, Z., Shi, M., \& Liang, Y. (2020). Imaging characteristics of initial chest computed tomography and clinical manifestations of patients with COVID-19 pneumonia. Japanese Journal of Radiology, 38(6):533-538. doi:10.1007/s11604-020-00973-x

Goethals, L., Barth, N., Guyot, J., Hupin, D., Celarier, T., \& Bongue, B. (2020). Impact of home quarantine on physical activity for older adults living at home during the COVID-19 pandemic: qualitative interview study. JMIR Aging, 3(1), el9007. doi:10.2196/19007

Gone, J. P., Hartmann, W. E., Pomerville, A., Wendt, D. C., Klem, S. H., \& Burrage, R. L. (2019). The impact of historical trauma on health outcomes for Indigenous populations in the USA and Canada: a systematic review. American Psychologist, 74(1), 20-35. doi:10.1037/amp0000338

Goodridge, D., Lawson, J., Rennie, D., \& Marciniuk, D. (2010). Rural/ urban differences in health care utilization and place of death for persons with respiratory illness in the last year of life. Rural Remote Health, 10(2), 1349. 
NCN COVID-19 PREPAREDNESS PROCEDURES, Kyoon-Achan and Wright

Government of Canada. (2020a, April 24). Coronavirus disease (COVID-19): Outbreak update. Government of Canada. Retrieved from: https://www.canada.ca/en/public-health/services/ diseases/2019-novel-coronavirus-infection.htmlettopic=tilelink

Government of Canada. (2020b). Epidemiological summary of COVID-19 cases in Canada. Retrieved from: https://www.canada.ca/content/ dam/phac-aspc/documents/services/diseases/2019-novel-corona virus-infection/surv-covid 19-epi-update-eng.pdf

Government of Canada. (2020c, April 24). Government of Canada takes action on COVID-19. Retrieved from: https://www.canada.ca/en/ public-health/services/diseases/2019-novel-coronavirus-infection/ canadas-reponse/government-canada-takes-action-covid-19.html

Government of Manitoba. (2020, April 24). Manitoba COVID-19 Updates. Government of Manitoba. Retrieved from: https://www.gov. $\mathrm{mb} . \mathrm{ca} /$ covid19/updates/index.html

Gracey, M., \& King, M. (2009). Indigenous health part 1: determinants and disease patterns. Lancet, 374(9683), 65-75. doi:10.1016/ s0140-6736(09)60914-4

Greenwood, M. L., \& de Leeuw, S. N. (2012). Social determinants of health and the future well-being of Aboriginal children in Canada. Paediatrics \& Child Health, 1777), 381-384.

Guan, W. J., Ni, Z. Y., Hu, Y., Liang, W. H., Ou, C. Q., He, J. X., ... Liv, L. (2020). Clinical characteristics of coronavirus disease 2019 in China. New England Journal of Medicine, 382, 1708-1720. doi:10.1056/NEJMoa2002032

Guo, Y. R., Cao, Q. D., Hong, Z. S., Tan, Y. Y., Chen, S. D., Jin, H. J., ... Tan, K. (2020). The origin, transmission and clinical therapies on coronavirus disease 2019 (COVID-19) outbreak-an update on the status. Military Medical Research, 7(1), 11. doi:10.1186/ s40779-020-00240-0

Haiizadeh, M., Hu, M., Bombay, A., \& Asada, Y. (2018). Socioeconomic inequalities in health among Indigenous peoples living off-reserve in Canada: trends and determinants. Health Policy, 122(8), 854-865. doi:10.1016/i.healthpol.2018.06.011

Harasemiw, O., Milks, S., Oakley, L., Lavallee, B., Chartrand, C., Mcleod, L., ... Komenda, P. (2018). Remote dwelling location is a risk factor for CKD among Indigenous Canadians. Kidney International Reports, 3(4), 825-832. doi:10.1016/j.ekir.2018.02.002

Indigenous Services Canada. (2020, April 24). COVID-19: First Nations Community Guide on Accessing Additional Supports. Government of Canada. Retrieved from: https://www.sac-isc.gc.ca/ eng/1584819394157/1584819418553

Lai, C. C., Shih, T. P., Ko, W. C., Tang, H. J., \& Hsueh, P. R. (2020). Severe acute respiratory syndrome coronavirus 2 (SARS-CoV-2) and coronavirus disease-2019 (COVID-19): the epidemic and the challenges. International Journal of Antimicrobial Agents, 55(3), 105924. doi:10.1016/i.ijantimicag.2020.105924

Li, L., Yang, Z., Dang, Z., Meng, C., Huang, J., Meng, H., ... Wang, D. (2020). Propagation analysis and prediction of the COVID-19. Infectious Disease Modeling, 5, 282-292. doi:10.1016/i. idm.2020.03.002

Liang, W. H., Guan, W. J., Li, C. C., Li, Y. M., Liang, H. R., Zhao, Y., ... Liu, X. (2020). Clinical characteristics and outcomes of hospitalised patients with COVID-19 treated in Hubei (epicenter) and outside Hubei (non-epicenter): a nationwide analysis of China. European Respiratory Journal, 2000562. doi:10.1183/13993003.00562-2020

Mawson, A. R. (2005). Understanding mass panic and other collective responses to threat and disaster. Psychiatry, 68(2), 95-113. doi:10.1521/psyc.2005.68.2.95

Mostaco-Guidolin, L. C., Bowman, C. S., Greer, A. L., Fisman, D. N., \& Moghadas, S. M. (2012). Transmissibility of the 2009 HIN1 pandemic in remote and isolated Canadian communities: a mod- elling study. British Medical Journal Open, 2(5). doi:10.1136/ bmjopen-2012-001614

Mostaco-Guidolin, L. C., Greer, A., Sander, B., Wu, J., \& Moghadas, S. M. (2011). Variability in transmissibility of the $2009 \mathrm{HIN1}$ pandemic in Canadian communities. BMC Research Notes, 4, 537. doi:10.1186/1756-0500-4-537

Mostaco-Guidolin, L. C., Towers, S. M., Buckeridge, D. L., \& Moghadas, S. M. (2013). Age distribution of infection and hospitalization among Canadian First Nations populations during the 2009 HIN1 pandemic. American Journal of Public Health, 103(2), e39-e44. doi:10.2105/ajph.2012.300820

National Collaborating Centre for Aboriginal Health, T. (2016). Pandemic planning in Indigenous communities: lessons learned from the 2009 HINT influenza pandemic in Canada. Retrieved from: www. nccah-ccnsa.ca/Publications/Lists/Publications/Attachments/176/ NCCAH-FS-InfluenzaPandemic-PartO3-Halseth-EN-Web.pdf

Truth and Reconciliation Commission (TRC). (2015). Truth and Reconciliation Commission of Canada: Calls to Action. http://trc.ca/assets/ pdf/Calls_to_Action_English2.pdf

Wang, L., Duan, Y., Zhang, W., Liang, J., Xu, J., Zhang, Y., ... Wu, C. (2020). Epidemiologic and clinical characteristics of 26 cases of COVID-19 arising from patient-to-patient transmission in Liaocheng, China. Clinical Epidemiology, 12, 387-391. doi:10.2147/clep. S249903

World Health Organization. (2020a, March 11). WHO Director-General's opening remarks at the media briefing on COVID-19. https:// www.who.int/dg/speeches/detail/who-director-general-sopeningremarks-at-the-media-briefing-oncovid-19

World Health Organization. (2020b). Coronavirus disease (COVID-19) Situation Report - 102 (102). WHO. https://www.who.int/docs/ default-source/coronaviruse/situation-reports/20200501-covid19-sitrep.pdf? sfvrsn=742f4a18_2

Wu, F., Zhao, S., Yu, B., Chen, Y.-M., Wang, W., Song, Z.-G., ... Hu, Y. (2020). A new coronavirus associated with human respiratory disease in China. Nature, 579(7798), 265-269. doi:10.1038/ s41586-020-2008-3

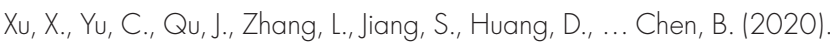
Imaging and clinical features of patients with 2019 novel coronavirus SARS-CoV-2. European Journal of Nuclear Medicine and Molecular Imaging, 4715), 1275-1280. doi:10.1007/s00259-020-04735-9

Yang, C., Qiu, X., Fan, H., Jiang, M., Lao, X., Zeng, Y., \& Zhang, Z. (2020). Coronavirus disease 2019: reassembly attack of corona virus. International Journal of Environmental Health Research, 1-9. do i: $10.1080 / 09603123.2020 .1747602$

Zhang, F. Y., Qiao, Y., \& Zhang, H. (2020). CT imaging of the COVID-19. Journal of the Formosan Medical Association. doi:10.1016/i. ifma.2020.04.006

Zhang, J., Litvinova, M., Liang, Y., Wang, Y., Wang, W., Zhao, S., ... Wu, Q. (2020). Changes in contact patterns shape the dynamics of the COVID-19 outbreak in China. Science. doi:10.1126/science. abb8001

Zhang, Y., \& Ma, Z. F. (2020). Impact of the COVID-19 pandemic on mental health and quality of life among local residents in Liaoning Province, China: a cross-sectional study. International Journal of Environmental Research and Public Health, 17(7). doi:10.3390/ ijerph17072381 